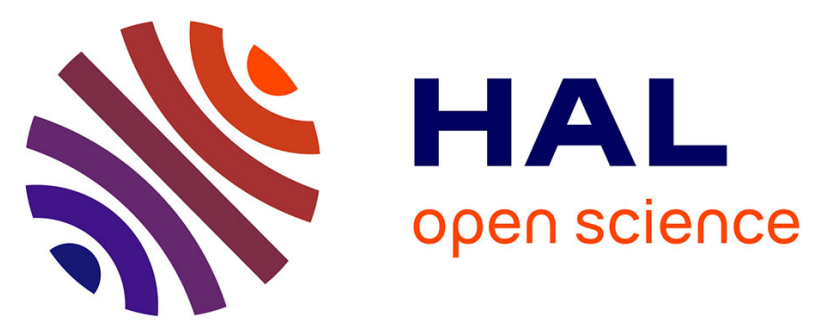

\title{
The relationship between hearing loss in older adults and depression over 12 years: Findings from the Three-City prospective cohort study
}

Suzanne Cosh, Isabelle Carrière, Vincent Daien, Hélène Amieva, Christophe Tzourio, Cécile Delcourt, Catherine Helmer

\section{To cite this version:}

Suzanne Cosh, Isabelle Carrière, Vincent Daien, Hélène Amieva, Christophe Tzourio, et al.. The relationship between hearing loss in older adults and depression over 12 years: Findings from the Three-City prospective cohort study. International Journal of Geriatric Psychiatry, 2018, 33 (12), pp.1654 - 1661. 10.1002/gps.4968 . inserm-01935969

\section{HAL Id: inserm-01935969 https://www.hal.inserm.fr/inserm-01935969}

Submitted on 27 Nov 2018

HAL is a multi-disciplinary open access archive for the deposit and dissemination of scientific research documents, whether they are published or not. The documents may come from teaching and research institutions in France or abroad, or from public or private research centers.
L'archive ouverte pluridisciplinaire HAL, est destinée au dépôt et à la diffusion de documents scientifiques de niveau recherche, publiés ou non, émanant des établissements d'enseignement et de recherche français ou étrangers, des laboratoires publics ou privés. 
The relationship between hearing loss in older adults and depression over 12 years: findings from the Three-City prospective cohort study

Running head: Hearing loss and depression in older adults over 12 years

Authors: $\operatorname{Dr~S~Cosh}{ }^{1,2 ¥}, \operatorname{Dr} I$ Carriere ${ }^{3}, \operatorname{Dr} V$ Daien $^{3,4}, \operatorname{Dr~H~Amieva}^{5}$, Prof C Tzourio ${ }^{6}$, $\underline{\operatorname{Dr} C \text { Delcourt }}{ }^{1}, \operatorname{Dr} C$ Helmer $^{1}$ and the Sense-Cog Consortium ${ }^{*}$

* Corresponding author

School of Psychology and Behavioural Science

University of New England,

Armidale NSW 2351, Australia

scosh@une.edu.au

ph: +61267732073

${ }^{1}$ Univ. Bordeaux, Inserm, Bordeaux Population Health Research Center, team

LEHA, UMR 1219, F-33000 Bordeaux, France

${ }^{2}$ School of Psychology and Behavioural Science, University of New England, Armidale NSW 2351, Australia

${ }^{3}$ INSERM, Univ Montpellier, Neuropsychiatry: Epidemiological and Clinical Research, Montpellier, France

${ }^{4}$ Department of Ophthalmology, Gui De Chauliac Hospital, Montpellier, F-34000, France

5 Univ. Bordeaux, Inserm, Bordeaux Population Health Research Center, team SEPIA, UMR 1219, F-33000 Bordeaux, France

${ }^{6}$ Univ. Bordeaux, Inserm, Bordeaux Population Health Research Center, team HEALTHY, UMR 1219, CHU Bordeaux, F-33000 Bordeaux, France 


\section{Acknowledgments}

“SENSE-Cog has received funding from the European Union's Horizon 2020 research and innovation programme under grant agreement No 668648".

The Three-City study is conducted under a partnership agreement between the Institut National de la Santé et de la Recherche Médicale (INSERM), the University Bordeaux 2 Victor Segalen and Sanofi-Aventis. The Fondation pour la Recherche Médicale funded the preparation and initiation of the study. The Three-City study is also supported by the Caisse Nationale Maladie des Travailleurs Salariés, Direction Générale de la Santé, MGEN, Institut de la Longévité, Conseils Régionaux d'Aquitaine et Bourgogne, Fondation de France, Ministry of Research-INSERM Programme "Cohortes et collections de données biologiques", Agence Nationale de la Recherche ANR PNRA 2006 and LongVie 2007, and the "Fondation Plan Alzheimer" (FCS 2009-2012).

Word Count: 3068

Keywords: Hearing impairment, healthy ageing, mental wellbeing, sensory loss

Key Points:

- $\quad$ The relationship between hearing loss and depression in older adults is unclear and longitudinal examinations are rare

- $\quad$ Older adults with self-reported HL were more likely to have depression symptoms and a diagnosis of depression

- $\quad$ Over 12 years, mild and severe HL were associated with onset of depression symptoms, but no incident depression diagnosis 


\section{Abstract}

Objective: The present study aims to examine the longitudinal relationship between hearing loss $(\mathrm{HL})$ with depression in older adults over 12 years of follow up.

Method: 8344 French community-dwelling adults aged 65 and above participated in the Three-City prospective population-based study. Baseline relationships between self-reported mild and severe HL with depression - assessed by both the Mini International Neuropsychiatric Interview and by the Centre for Epidemiology Studies Depression scale - were explored using logistic regression analyses. Logistic mixed models assessed whether baseline HL was associated with incident depression diagnosis or symptom onset over 12 years in those who were depression-free at baseline.

Results: At baseline, mild and severe HL were associated with depression symptoms as assessed by the CESD (OR $=1.2995 \% \mathrm{Cls} 1.14-1.47$; OR $=1.5195 \%$ Cls 1.22-1.87; respectively), although only mild HL was significantly related to major depression diagnosis $(\mathrm{OR}=1.51,95 \%$ Cls $1.07-2.12)$. Over 12 years, mild and severe HL were associated with incident depression as assessed by the CESD in those without depression at baseline $(\mathrm{OR}=1.3695 \% \mathrm{Cls} 1.15-1.61$; OR $=1.6995 \%$ Cls 1.15-2.30; respectively), but was not associated with a major depression diagnosis.

Conclusions: Both mild and severe thresholds of $\mathrm{HL}$ are associated with depression symptoms over time, but not with incident diagnosis of major depression. Improved and ongoing detection of subthreshold depression amongst older adults with HL may improve quality of life for this population. 


\section{Introduction}

Hearing losses $(\mathrm{HL})$ are common among older adults, with up to one third aged over 65 experiencing HL (WHO, 2012). HL substantially contributes to burden of disease (Mathers and Loncar, 2006, Wittchen et al., 2011) by increasing disability (Armstrong et al., 2016). Poorer quality of life (Chia et al., 2007, Eisele et al., 2015) and mental health has also been reported amongst those with $\mathrm{HL}$ (Armstrong et al., 2016, Heine and Browning, 2014). Older adults with HL experience less emotional vitality (i.e. less personal mastery and more psychological symptoms) (Contrera et al., 2016), and increased anxiety symptoms (Contrera et al., 2017, Cosh et al., 2017). Concomitantly older adults with $\mathrm{HL}$ also report lower levels of happiness and selfefficacy than those without HL (Contrera et al., 2016, Kramer et al., 2002).

Given that $\mathrm{HL}$ has been shown to significantly impinge upon the mental wellbeing of older adults, the extent to which $\mathrm{HL}$ might be related to depression has also been examined. Limited evidence to date indicates a cross-sectional relationship between HL and depression amongst older adults (Gopinath et al., 2009, Lee et al., 2010), and adults of all ages (Ciesla et al., 2016, Li et al., 2014). Notably reductions in activities of daily living (Gopinath et al., 2012), as well as self-efficacy and social network (Mener et al., 2013) often observed in HL, alongside increased loneliness (Pronk et al., 2013), are possible mechanisms underlying the observed relationships.

However, findings regarding the relationship between $\mathrm{HL}$ and depression remain equivocal (Mener et al., 2013, Tambs, 2004). Furthermore, longitudinal examinations of $\mathrm{HL}$ and depression are scant, and the findings thus far are also contradictory. A Taiwanese study showed that over 12 years, $\mathrm{HL}$ was associated with increased incidence of depression relative to matched controls (Hsu et al., 2016). 
Concomitantly, an increased rate of depression symptoms following the onset of $\mathrm{HL}$ has also been observed (Kiely et al., 2013). Conversely, in a Dutch cohort, no relationship between $\mathrm{HL}$ and depression was found, although $\mathrm{HL}$ was associated with increased loneliness amongst men (Pronk et al., 2013, Pronk et al., 2014). HL has also been shown to have a cross-sectional relationship with depression symptoms in a sample of older Norwegian adults, but this relationship was no longer significant after six years (Cosh et al., 2017). Such variations in findings appear to reflect a range of methodological differences between studies. Notably, assessment and classification of depression has varied substantially across studies, with differential findings observed both cross-sectionally (Gopinath et al., 2009) and longitudinally depending on the classification of depression outcome. Further methodological variations include assessment of $\mathrm{HL}$ (Lee et al., 2010), adjustment for health or psychosocial covariates, and the average age of the sample, with the $\mathrm{HL}$ and depression relationships reportedly stronger amongst younger adults (Tambs, 2004).

Additional studies are thus needed to better ascertain the long-term relationship between HL and depression (Contrera et al., 2016). Moreover, comparison of depression diagnosis compared with presence of depression symptoms is needed to further clarify the currently inconsistent findings. Therefore, the present study aims to examine the association between $\mathrm{HL}$ with depression over 12 years amongst older adults, specifically examining depression outcome as both diagnosis of Major Depressive Disorder (MDD) and presence of elevated depression symptoms. 


\section{Methods}

This study forms part of the SENSE-Cog multi-phase research programme, funded by the European Union Horizon 2020 programme. SENSE-Cog aims to promote mental well-being in older adults with sensory and cognitive impairments (http://www.sense-cog.eu/). The first work package of this project aims to better understand the links between sensory, cognitive and mental ill-health in older Europeans (Cosh et al., Forthcoming).

Sample

Participants were recruited as part of the multi-center Three-City study (The 3C Study Group, 2003), a population-based cohort of community-dwelling persons aged 65 years and over. Between 1999 and 2001, 9294 participants were recruited from the electoral rolls of three French cities (Bordeaux, Dijon and Montpellier). A standardized evaluation with a face-to-face interview, as well as clinical examinations were undertaken at baseline as well as 2-3 year intervals for up to 12 years (see Figure 1). Of the initial sample, 7560 (90.6\%) participated in at least one wave of follow up over the 12-year period; 116 participants had died before the first follow-up and 1411 by the end of the 12-year period (for a detailed overview of 3C sampling and methods see The 3C Study Group, 2003). The study protocol was approved by the Ethical Committees of the University-Hospitals of Bicêtre and Nîmes (France) and written informed consent was obtained from each participant. 


\section{Depression Measures}

The Mini International Neuropsychiatric Interview (MINI) (Sheehan et al., 1998) assessed current MDD diagnosis, according to DSM-IV criteria. The MINI is a standardized and well validated diagnostic interview, which has been validated in France (Lecrubier et al., 1997). The MINI was administered at baseline, as well as at 7,10 and 12 years. Prevalent cases were defined as current MDD at baseline and incident cases were defined as those presenting with a new and current diagnosis of MDD at a follow-up visit.

Depression symptoms were assessed via the 20-item Centre for Epidemiology Studies-Depression Scale (Radloff, 1977) at all follow-up points. The CESD is a wellvalidated and reliable self-report depression screening tool. The French version of the CESD has also been validated in a population of community dwelling French adults (Morin et al., 2011). Items are rated on a 4 point scale indicating symptom frequency in the past week, with higher scores indicative of greater symptom severity. Participants with a score $\geq 16$ were classified as having depression symptoms (Lewinsohn et al., 2003).

Hearing Measurement

Self-reported Hearing Loss was assessed during standardized face-to-face interview administrated by trained psychologists or nurses at each follow up time point. HL was determined by the response to the question "do you hear what is said in everyday conversation?" Participants were given four response categories (yes without difficulties; some difficulties hearing someone who speaks normally; 
difficulties hearing someone who speaks loudly; no/deafness). Mild HL was classified as self-reported difficulty understanding a conversation (normal or loud speaking) and severe HL was classified as self-reported deafness or inability to hear a conversation.

\section{Covariates}

Socio-demographic and health-related information was collected during the standardized interview. These included education level (elementary, secondary, higher education), monthly income ( $<€ 760, € 760-2280,>€ 2280$, withheld/missing), and marital status (married/de facto, single/widowed/divorced). Information regarding alcohol consumption ( $<10,10-40,>40$ grams per day), tobacco use (current-, past -, or non-smoker), and falls during the past 12 months was also obtained. A composite score representing functional ability was calculated based the Rosow-Breslau scale, the Lawton-Brody Brody Instrumental Activities of Daily living (IADL) scale and the Katz Index of Independence in Activities of Daily Living (categorized as autonomous; dependent for mobility; mobility and IADL limitations; and dependent in 3+ areas; missing) (Barberger-Gateau et al., 2000). History of myocardial infarction, diabetes (fasting glycemia $\geq 7 \mathrm{mmol} / \mathrm{L}$ and/or anti-diabetic treatment), and use of psychotropic medication in the past month (ATC classification codes: N05A-C, N06A-B) was obtained. During the medical examination blood pressure was measured using a digital electronic tensiometer OMRON M4. Hypertension was defined using the $140 / 90 \mathrm{mmHg}$ threshold or treatment with blood-pressure lowering drugs (ATC codes: C02, C03, C07, C08). Cognitive functioning was also assessed using the Mini Mental State Examination (MMSE; $<24 \geq 24$ ). 


\section{Statistical Analysis}

Socio-demographic and health characteristics were compared according to sensory loss using chi-squares and one-way ANOVAs. Baseline associations between HL with both MDD diagnosis and depression symptoms (16+ CESD score) were examined using logistic regression analyses. The longitudinal associations between baseline $\mathrm{HL}$ and depression were examined using mixed logistic models (Carriere and Bouyer, 2002). Logistic mixed models take into account within-subject correlation and model the individual's evolutions of depression over time across the 12 years of follow-up. Logistic mixed models allow for the reversibility of outcomes, and are thus sensitive to remitted cases of depression, and are also robust to missing data. The effect of baseline HL on incident MDD in those free of MDD at baseline and the relationship of baseline $\mathrm{HL}$ with incident depression symptoms in those free of depression symptoms at baseline were examined.

For each analysis, three models were undertaken to provide a more comprehensive understanding of the relative impact of psychosocial and physical health covariates on the HL-depression relationship. Model 1 adjusted for sex, study center, and age; Model 2 further adjusted for known psychosocial covariates; education, income, marital status, and psychotropic medication; and Model 3 also adjusted for physical health; functional ability, falls in past 12 months, hypertension, diabetes, smoking, alcohol, cognitive function (MMSE), and myocardial infarction. We also systematically searched for potential interactions between $\mathrm{HL}$ with sex, income and education level. Analyses were conducted using SAS 9.4 (SAS Institute, Inc., Cary, NC). 


\section{Results}

Of the 8344 participants with baseline hearing and depression data, $60.4 \%$ ( $\mathrm{n}$ $=5043)$ were female and mean age was $74.2(S D=5.5)$ years. At baseline, prevalence of mild $\mathrm{HL}$ was $30.7 \%(n=2558)$ and $7.8 \%(n=654)$ for severe $\mathrm{HL}$. Those with HL were older, more likely to be male, less educated, more commonly a pastsmoker and in poorer physical health on all assessed covariates (see Table 1). Baseline prevalence of MDD was 1.9\% ( $n=154)$ with a further $202(2.2 \%)$ cases of incident MDD over 12 years. At baseline 20.1\% $(n=1679)$ reported depression symptoms, with a further $1484(22.3 \%)$ reporting onset of depression symptoms over follow-up. Both those with MDD and depression symptoms were more likely to be female, and unmarried (<.001). Those reporting depression symptoms also consumed more alcohol and had a lower income (<.001).

At baseline (Table 2), mild but not severe $\mathrm{HL}$ was associated with MDD $(\mathrm{OR}=$ $1.51,95 \%$ Cls $1.07-2.12 ; \mathrm{OR}=1.4895 \%$ Cls $0.79-2.79$; respectively) in all models, whereas both mild and severe $\mathrm{HL}$ were associated with depression symptoms $(\mathrm{OR}=$ $1.2995 \%$ Cls $1.14-1.47 ; \mathrm{OR}=1.5195 \%$ Cls $1.22-1.87$; respectively). HL was not associated with incident MDD over 12 years (Table 3). On the other hand, both mild and severe $\mathrm{HL}$ were related to incident depression symptoms $(\mathrm{OR}=1.3695 \% \mathrm{Cls}$ $1.15-1.61 ; \mathrm{OR}=1.6995 \% \mathrm{Cls} 1.15-2.30$; respectively) in all models. No interactions were significant. 


\section{Discussion}

This study contributes to the currently limited and equivocal literature examining the longitudinal relationship between $\mathrm{HL}$ and depression. Those with selfreported $\mathrm{HL}$ were more likely to have elevated depression symptoms and diagnosed MDD at baseline. Furthermore, mild and severe $\mathrm{HL}$ were also associated with incident depression symptoms over 12 years in those depression-free at baseline, however $\mathrm{HL}$ was to related to incident MDD.

Consistent with prior findings, our results showed a significant cross-sectional relationship between $\mathrm{HL}$ and depression (Gopinath et al., 2009, Lee et al., 2010), and both mild and severe HL thresholds were related to elevated depression symptoms. Although differential relationships between $\mathrm{HL}$ and depression have been reported depending on how depression was assessed (Gopinath et al., 2009), associations between HL and MDD diagnosis have been less commonly explored (Mener et al., 2013). Our results showed that mild HL was associated with MDD diagnosis. Results for severe HL were in the same direction, however, did not reach statistical significance. This may be due to a reduced statistical power owing to the lower numbers reporting severe HL.

Furthermore, our results contribute to the small and contradictory evidence regarding the longitudinal association between $\mathrm{HL}$ and depression. Previous longitudinal studies examining severity of depression symptoms have found no association between HL and depression (Pronk et al., 2013, Cosh et al., 2017), whereas difference in depression symptoms pre- and post- HL onset have been observed (Kiely et al., 2013). Our findings highlight a significant longitudinal association between $\mathrm{HL}$ with presence of depression symptoms. Thus $\mathrm{HL}$ appears to 
be related to presence of elevated depression symptoms, rather than directly impinging on symptom severity.

Although an association between $\mathrm{HL}$ and incident MDD has been reported previously (Hsu et al., 2016), we did not find an association with MDD. Differences in findings might be explained by the older mean age of our sample, with some evidence suggesting a stronger relationship between $\mathrm{HL}$ and depression in younger ages (Tambs, 2004). Notably, although the result was non-significant, an increased OR for MDD was observed for severe HL. It is likely that due to the few cases of incident MDD, our lack of an association may be due to analyses being underpowered.

Our results further suggest that differences in prior findings are likely reflective of varying methods of assessing depression. We found that $\mathrm{HL}$ was associated over time with presence of elevated symptoms, rather than depression diagnosis. The relationship with presence of increased symptomatology but lack of an association with MDD might reflect that subsyndromal depression is more common in older adults than major depression (Blazer, 2003); with self-report depression measures (such as the CESD) frequently used in the sensory loss literature failing to distinguish between MDD and subsyndromal depression.

Notably, however, elevated depression symptoms or subsyndromal depression can result in poor outcomes including increased mortality rates (Pennix et al., 1999a) and suicidal ideation (Geiselmann et al., 2001). Subsyndromal depression substantially contributes to reduced quality of life, increased disability (Pennix et al., 1999b) and increased negative attitudes towards ageing (Chachamovich et al., 2008). Thus even in the absence of an MDD diagnosis, treatment and intervention for 
depression symptoms remain important in the elderly with HL. Given that depression symptoms often go unnoticed and undiagnosed in the elderly (Teresi et al., 2001), and communication barriers frequently limit access to mental health support for those with HL (Sheppard and Badger, 2010, Turner et al., 2007), targeted intervention may be beneficial for this population.

A reduction in the ability to carry out activities of daily living is a proposed mechanism contributing to the association between $\mathrm{HL}$ and depression (Chou, 2008), however adjustment for functional abilities did not attenuate results. Odds ratios in our studies remained similar across levels of adjustment, suggesting that other common processes might better explain these relationships. Communication difficulties observed in HL (Kiely et al., 2013, McDonnall, 2009) may underlie the association with depression, especially through increased social isolation and Ioneliness (Pronk et al., 2011, Schneider et al., 2012); with perceived lack of social support associated with depression onset (Pennix et al., 1999b). Furthermore, reductions in help seeking (Sheppard and Badger, 2010) and increases in comorbid anxiety (Cosh et al., 2017) might also contribute to the depression and HL relationship.

\section{Strengths and Limitations}

Strengths of this study include the length of follow up and large sample size. Moreover, this study substantially contributes to the current $\mathrm{HL}$ and depression literature, not only by providing a rare longitudinal examination, but also by exploring depression both as an MDD diagnosis and as the presence of elevated depression symptoms. Such analysis allowed for increased insight into the nature of associations 
of $\mathrm{HL}$ and depression in older adults. Limitations include that $\mathrm{HL}$ was self-reported. Such self-reports may represent underestimates of actual $\mathrm{HL}$, due to perceptions that hearing decline is a natural part of aging. Conversely, those who have depression might be more likely to self-report $\mathrm{HL}$, or concentration deficits associated with depression might increase the likelihood of difficultly hearing a conversation. Although, given that those with baseline depression were excluded from longitudinal analyses, it appears that the HL-depression association extends beyond only selfreporting bias. Although relationships remained significant after adjustment for cognitive functioning, the extent to which underlying cognitive decline might have influenced self-report $\mathrm{HL}$ and the ability to hear a conversation cannot be fully ascertained. Furthermore, from this study we cannot exclude the possibility that depression onset might have been a prodromal aspect of dementia. However, given the dearth of longitudinal studies of $\mathrm{HL}$ and depression, our findings contribute valuable insight, although ongoing research with objective assessments of HL would be invaluable to corroborate such associations.

Although a CESD cut off score of 16 has empirical support, there is also debate as to the most appropriate cut off score (see Vilagut et al., 2016). Different thresholds may result in differences in findings. MDD was assessed only at three time points, thus additional MDD cases that may have occurred and remitted between assessments were not included. Our MDD results were also likely underpowered, especially for severe $\mathrm{HL}$ and we cannot be certain of the lack of associations. 


\section{Conclusion}

Older adults with self-reported HL have poorer mental health outcomes, in particular subthreshold depression over time. Both mild and severe self-reported HL are associated with depression symptoms at baseline as well as over 12 years.

Especially given possible communication and help-seeking barriers in $\mathrm{HL}$, increased focus on assessment and identification of depression, including subthreshold symptomatology, may be warranted to improve quality of life amongst older adults with HL. Concomitantly, improved identification and management of HL might crucially limit depression amongst older adults. 


\section{References}

Armstrong, T. W., Suyra, S., Elliott, T. R., Brossart, D. F. \& Burdine, J. N. 2016. Depression and health-related quality of life among persons with sensory disabilities in a health professional shortage area. Rehabil Psychol, 61, 240-50.

Barberger-Gateau, P., Rainville, C., Letenneur, L. \& Dartigues, J. 2000. A hierarchical model of domains of disablement in the elderly: a longitudinal approach. Disability and Rehabilitation, 22, 308-317.

Blazer, D. G. 2003. Depression in Late Life: Review and Commentary. Journal of Gerontology: Medical Sciences, 58A, 249-265.

Carriere, I. \& Bouyer, J. 2002. Choosing marginal or random-effects models for longitudinal binary reposnes: application to self-reported disability among older persons. $B M C$ Med Res Methodol, 2, 15.

Chamovich, E., Fleck, M., Laidlaw, K. \& Power, M. 2008. Impact of Major Depression and Subsyndromal Symptoms on Quality of Life and Attitudes Toward Aging in an International Sample of Older Adults. The Gerontologist, 48, 593-602.

Chia, E. M., Wang, J. J., Rochtchina, E., Cumming, R. R., Newall, P. \& Mitchell, P. 2007. Hearing impairment and health-related quality of life: the Blue Mountains Hearing Study. Ear Hear, 28, 187-95.

Chou, K. L. 2008. Combined effect of vision and hearing impairment on depression in older adults: evidence from the English Longitudinal Study of Ageing. J Affect Disord, 106, 191-6.

Ciesla, K., Lewandowska, M. \& Skarzynski, H. 2016. Health-related quality of life and mental distress in patients with partial deafness: preliminary findings. Eur Arch Otorhinolaryngol, 273, 767-76.

Contrera, K. J., Betz, J., Deal, J., Choi, J. S., Ayonayon, H. N., Harris, T., Helzner, E., Martin, K. R., Mehta, K., Pratt, S., Rubin, S. M., Satterfield, S., Yaffe, K., Simonsick, E. M. \& Lin, F. R. 2017. Association of Hearing Impairment and Anxiety in Older Adults. $J$ Aging Health, 29, 172-184.

Contrera, K. J., Betz, J., Deal, J., Choi, J. S., Ayonayon, H. N., Harris, T., Helzner, E., Martin, K. R., Mehta, K., Pratt, S., Rubin, S. M., Satterfield, S., Yaffe, K., Simonsick, E. M. \& Lin, F. R. 2016. Association of Hearing Impairment and Emotional Vitality in Older Adults. J Gerontol B Psychol Sci Soc Sci.

Cosh, S., Dawes, P., Helmer, C., Multu, U., Von Hanno, T., Constantinidou, F., Maharani, A., Bertelsen, G., Nael, V., Tampubolom, G., Cougnard-Gregoire, A., Meester-Smor, M., Schirmer, H., Tiemeier, H. W., Ikram, M. A., Leroi, I., Klaver, C. C., Pendleton, N. \& Delcourt, C. Forthcoming. The interrelationships between sensory impairment, cognitive function and mental wellbeing in older adults over time: Design of the SENSE-COG epidemiology project.

Cosh, S., Von Hanno, T., Helmer, C., Bertelsen, G., Delcourt, C. \& Schirmer, H. 2017. The association amongst visual, hearing, and dual sensory loss with depression and anxiety over 6 years: The Tromso Study. Int J Geriatr Psychiatry.

Eisele, M., Kaduszkiewicz, H., Konig, H. H., Lange, C., Wiese, B., Prokein, J., Weyerer, S., Werle, J., Riedel-Heller, S. G., Luppa, M., Heser, K., Koppara, A., Mosch, E., Weeg, D., Fuchs, A., Pemtzek, M., Maier, W., Scherer, M. \& Hajek, A. 2015. Determinants of health-related quality of life in older primary care patients: results of the longitudinal observational AgeCoDe Study. Br J Gen Pract, 65, e716-23.

Geiselmann, B., Linden, M. \& Helmchen, H. 2001. Psychiatrists' diagnoses of subthreshold depression in old age: frequency and correlates. Psychological Medicine, 31, 51-63. 
Gopinath, B., Schneider, J., McMahon, C. M., Teber, E., Leeder, S. R. \& Mitchell, P. 2012. Severity of age-related hearing loss is associated with impaired activities of daily living. Age Ageing, 41, 195-200.

Gopinath, B., Wang, J. J., Schneider, J., Burlutsky, G., Snowdon, J., McMahon, C. M., Leeder, S. R. \& Mitchell, P. 2009. Depressive symptoms in older adults with hearing impairments: the Blue Mountains Study. J Am Geriatr Soc, 57, 1306-8.

Heine, C. \& Browning, C. J. 2014. Mental health and dual sensory loss in older adults: a systematic review. Front Aging Neurosci, 6, 83.

Hsu, W. T., Hsu, C. C., Wen, M. H., Lin, H. C., Tsai, H. T., Su, P., Sun, C. T., Lin, C. L., Hsu, C. Y., Chang, K. H. \& Hsu, Y. C. 2016. Increased risk of depression in patients with acquired sensory hearing loss: A 12-year follow-up study. Medicine (Baltimore), 95, e5312.

Kiely, K. M., Anstey, K. J. \& Luszcz, M. A. 2013. Dual sensory loss and depressive symptoms: the importance of hearing, daily functioning, and activity engagement. Front Hum Neurosci, 7, 837.

Kramer, S. E., Kapteyn, T. S., Kuik, D. J. \& Deeg, D. J. 2002. The Association of Hearing Impairment and Chronic Diseases With Psychosocial Health Status in Older Age. Journal of Aging and Health 14, 122-137.

LeCrubier, Y., Dunbar, G. C., Sheehan, D. V., Weiller, E., Amorim, P., Bonora, I., Sheehan, K. H. \& Janavs, J. 1997. The Mini International Neuropsychiatric Interview (MINI), a short diagnostic interview: reliability and validity according to the CIDI. European Psychiatry, 12.

Lee, A. T., Tong, M. C., Yuen, K. C., Tang, P. S. \& Vanhasselt, C. A. 2010. Hearing impairment and depressive symptoms in an older chinese population. Journal of Otolaryngology - Head and Neck Surgery, 39, 498-503.

Lewinsohn, P. M., Pettit, J. W., Joiner, T. E., JR. \& Seeley, J. R. 2003. The symptomatic expression of major depressive disorder in adolescents and young adults. $J$ Abnorm Psychol, 112, 244-52.

Li, C. M., Zhang, X., Hoffman, H. J., Cotch, M. F., Themann, C. L. \& Wilson, M. R. 2014. Hearing impairment associated with depression in US adults, National Health and Nutrition Examination Survey 2005-2010. JAMA Otolaryngology - Head and Neck Surgery, 140, 293-302.

Mathers, C. D. \& Loncar, D. 2006. Projections of global mortality and burden of disease from 2002 to 2030. PLoS Med, 3, e442.

McDonnall, M. C. 2009. The effects of developing a dual sensory loss on depression in older adults: a longitudinal study. J Aging Health, 21, 1179-99.

Mener, D. J., Betz, J., Genther, D. J., Chen, D. \& Lin, F. R. 2013. Hearing loss and depression in older adults. J Am Geriatr Soc, 61, 1627-9.

Morin, A. J., Moullec, G., Maiano, C., Layet, L., Just, J. L. \& Ninot, G. 2011. Psychometric properties of the Center for Epidemiologic Studies Depression Scale (CES-D) in French clinical and nonclinical adults. Rev Epidemiol Sante Publique, 59, 327-40.

Pennix, B. W. J. H., Geerlings, S. W., Deeg, D. J. H., Van Eijk, J. T., Van Tilburg, T. G. \& Beekman, A. T. F. 1999a. Minor and major depression and the risk of death in older persons. Archives of General Psychiatry, 56, 889-95.

Pennix, B. W. J. H., Leveille, S., Ferrucci, L., Van Eijk, J. T. \& Guralnik, J. M. 1999b. Exploring the effect of depression on physical disability: longitudinal evidence from the established populations for epidemiologic studies of the elderly. American Journal of Publlic Health, 89, 1346-52. 
Pronk, M., Deeg, D. J. \& Kramer, S. E. 2013. Hearing status in older persons: a significant determinant of depression and loneliness? Results from the longitudinal aging study amsterdam. Am J Audiol, 22, 316-20.

Pronk, M., Deeg, D. J., Smits, C., Twisk, J. W., Van Tilburg, T. G., Festen, J. M. \& Kramer, S. E. 2014. Hearing Loss in Older Persons: Does the Rate of Decline Affect Psychosocial Health? J Aging Health, 26, 703-723.

Pronk, M., Deeg, D. J., Smits, C., Van Tilburg, T. G., Kuik, D. J., Festen, J. M. \& Kramer, S. E. 2011. Prospective effects of hearing status on loneliness and depression in older persons: identification of subgroups. Int J Audiol, 50, 887-96.

Radloff, L. S. 1977. The CESD Scale: A self-report depression scale for research in the general population. Applied Psychological Measurement, 1, 385-401.

Schneider, J., Gopinath, B., McMahon, C., Teber, E., Leeder, S. R., Wang, J. J. \& MitchellL, P. 2012. Prevalence and 5-year incidence of dual sensory impairment in an older Australian population. Ann Epidemiol, 22, 295-301.

Sheehan, D. V., LeCrubier, Y., Sheehan. K.H., Amorim, P., Janavs, J., Weiller, E., Hergueta, T., Baker, R. \& Dundbar, G. C. 1998. The Mini-International Neuropsychiatric Interview (M.I.N.I.): the development and validation of a structured diagnostic psychiatric interview for DSM-IV and ICD-10. Journal of Clinical Psychiatry, 59, 2233.

Sheppard, K. \& Badger, T. 2010. The lived experience of depression among culturally Deaf adults. J Psychiatr Ment Health Nurs, 17, 783-9.

Tambs, K. 2004. Moderate effects of hearing loss on mental health and subjective well-being: results from the Nord-Trondelag Hearing Loss Study. Psychosom Med, 66, 776-82.

Teresi, J., Abrams, R., Holmes, D., Ramirez, M. \& Eimicke, J. 2001. Prevalence of depression and depression recognition in nursing homes. Soc Psychiatry Psychiatr Epidemiol, 36, 613-20.

The 3C Study Group 2003. Vascular factors and risk of dementia: design of the Three-City Study and baseline characteristics of the study population. Neuroepidemiology, 22, 316-25.

Turner, O., Windfuhr, K. \& Kapur, N. 2007. Suicide in deaf populations: a literature review. Ann Gen Psychiatry, 6, 26.

Vilagut, G., Forero, C. G., Barbaglia, G. \& Alonso, J. 2016. Screening for Depression in the General Population with the Center for Epidemiologic Studies Depression (CES-D): A Systematic Review with Meta-Analysis. PLOS ONE, 11, e0155431.

WHO 2012. Mortality and budren of diseases. World Health Organisation

Wittchen, H. U., Jacobi, F., Rehm, J., Gustavsson, A., Svensson, M., Jonsson, B., Olesen, J., Allgulander, C., Alonso, J., Faravelli, C., Fratiglioni, L., Jennum, P., Lieb, R., Maercker, A., Van Os, J., Preisig, M., Salvador-Carulla, L., Simon, R. \& Steinhausen, H. C. 2011. The size and burden of mental disorders and other disorders of the brain in Europe 2010. Eur Neuropsychopharmacol, 21, 655-79. 
Table 1: Baseline characteristics of the study population by hearing loss. Three-City Study 1999-2001, N=8344.

\begin{tabular}{|c|c|c|c|c|c|c|c|}
\hline \multirow[b]{2}{*}{ Age: Mean (SD) } & \multicolumn{2}{|c|}{$\begin{array}{c}\text { No hearing loss } \\
n=5132\end{array}$} & \multicolumn{2}{|c|}{$\begin{array}{l}\text { Mild Hearing } \\
\text { Loss } n=2558\end{array}$} & \multicolumn{2}{|c|}{$\begin{array}{l}\text { Severe Hearing } \\
\text { Loss } \mathrm{n}=654\end{array}$} & \multirow{2}{*}{$\begin{array}{c}\mathbf{p} \\
<.001^{\mathrm{a}}\end{array}$} \\
\hline & 73.3 & 5.1 & 74.8 & 5.6 & 78.1 & 6.2 & \\
\hline Female $(n, \%)$ & 3395 & 66.2 & 1342 & 52.5 & 306 & 46.8 & $<.001$ \\
\hline Education (reference: high) & & & & & & & $<.001$ \\
\hline Low & 1256 & 24.5 & 680 & 26.6 & 228 & 34.9 & $<.001$ \\
\hline Mid & 2931 & 57.2 & 1395 & 54.6 & 312 & 47.8 & $<.001$ \\
\hline Income (reference $=$ high) & & & & & & & .08 \\
\hline Low $(<€ 760)$ & 276 & 5.7 & 138 & 5.8 & 47 & 7.9 & .10 \\
\hline Mid $(€ 760-€ 2280)$ & 2864 & 59.3 & 1404 & 58.5 & 365 & 61.0 & .50 \\
\hline Withheld/missing & 302 & 5.9 & 157 & 6.1 & 56 & 8.6 & .03 \\
\hline Married & 3047 & 59.4 & 1559 & 61.0 & 396 & 60.6 & .41 \\
\hline Smoking(reference: non-smoker) & & & & & & & $<.001$ \\
\hline Current smoker & 297 & 5.8 & 141 & 5.5 & 33 & 5.1 & .70 \\
\hline Past smoker & 1542 & 30.1 & 967 & 37.8 & 265 & 40.5 & $<.001$ \\
\hline Psychotropic medication use & 1422 & 27.7 & 746 & 29.2 & 235 & 35.9 & $<.001$ \\
\hline Alcohol consumption (reference: high) & & & & & & & $<.001$ \\
\hline Low (>10 grams per day) & 3071 & 59.84 & 1411 & 55.16 & 365 & 55.81 & $<.001$ \\
\hline Moderate (10-40 per day) & 1760 & 34.29 & 938 & 36.67 & 233 & 35.63 & .12 \\
\hline Fall in past 12 months & 936 & 18.3 & 503 & 19.7 & 148 & 22.7 & .01 \\
\hline Hypertension & 3914 & 76.3 & 2032 & 79.6 & 531 & 81.2 & $<.001$ \\
\hline Myocardial infarction & 213 & 4.2 & 154 & 6.0 & 43 & 6.6 & $<.001$ \\
\hline MMSE $(<24)$ & 49 & 0.9 & 38 & 1.5 & 20 & 3.1 & $<.001$ \\
\hline $\begin{array}{l}\text { Functional ability (reference: } \\
\text { autonomous) }\end{array}$ & & & & & & & $<.001$ \\
\hline Dependent for mobility & 1803 & 36.2 & 997 & 40.2 & 272 & 43.3 & $<.001$ \\
\hline Mobility and IADL limitations & 319 & 6.4 & 234 & 9.4 & 133 & 21.2 & $<.001$ \\
\hline Dependent in $3+$ areas & 30 & 0.6 & 27 & 1.1 & 7 & 1.1 & .25 \\
\hline Missing & 145 & 2.8 & 79 & 3.1 & 26 & 4 & .25 \\
\hline Diabetes & 385 & 7.5 & 228 & 9.0 & 66 & 10.2 & .02 \\
\hline MDD (current diagnosis) & 85 & 1.7 & 58 & 2.3 & 11 & 1.9 & .18 \\
\hline Depression (CESD 16+) & 962 & 18.8 & 556 & 21.7 & 161 & 24.6 & $<.001$ \\
\hline
\end{tabular}

SD: Standard deviation, ${ }^{a}=$ determined by one-way ANOVA, all other $p$ values determine by Chi square tests

Except for age, results are presented as $\mathrm{n}, \%$. 
Table 2: Association of baseline hearing loss with baseline MDD and depression symptoms (CESD)

OR $\quad 95 \%$ Cis $\quad$ p

\section{MDD diagnosis}

Mild Hearing Loss

$\begin{array}{lcccc}\text { Model 1 } & 1.54 & 1.10 & 2.17 & .01 \\ \text { Model 2 } & 1.50 & 1.06 & 2.11 & .02 \\ \text { Model 3 } & 1.51 & 1.07 & 2.12 & .02\end{array}$

Severe Hearing Loss

$\begin{array}{lllll}\text { Model 1 } & 1.55 & 0.82 & 2.93 & .17 \\ \text { Model 2 } & 1.48 & 0.78 & 2.80 & .23 \\ \text { Model 3 } & 1.48 & 0.79 & 2.79 & .22\end{array}$

\section{Depression symptoms}

Mild Hearing Loss

$\begin{array}{lcccc}\text { Model 1 } & 1.33 & 1.17 & 1.50 & <.001 \\ \text { Model 2 } & 1.31 & 1.16 & 1.48 & <.001 \\ \text { Model 3 } & 1.29 & 1.14 & 1.47 & <.001\end{array}$

Severe Hearing Loss

$\begin{array}{lrrrr}\text { Model 1 } & 1.64 & 1.34 & 2.00 & <.001 \\ \text { Model 2 } & 1.59 & 1.29 & 1.96 & <.001 \\ \text { Model 3 } & 1.51 & 1.22 & 1.87 & <.001\end{array}$

Model 1: adjusted for sex, age, centre

Model 2: adjusted for sex, age, centre, education, income, marital status, psychotropic medication use Model 3: adjusted for sex, age, centre, education, income, marital status, psychotropic medication use, MMSE, functional ability, falls, BMI, hypertension, diabetes, smoking, alcohol consumption, and history of stroke and myocardial infarction

MDD analyses: Model $1 \mathrm{n}=8157$; Model $2 \mathrm{n}=8137$; Model $3 \mathrm{n}=8079$

Depression analyses: Model $1 \mathrm{n}=8344$; Model $2 \mathrm{n}=8328$; Model $3 \mathrm{n}=8268$ 
Table 3: Association of baseline hearing loss with incident MDD and depression symptoms (CESD)

OR $\quad 95 \%$ Cis $\quad$ p

\section{MDD diagnosis}

Mild Hearing Loss

$\begin{array}{lcccc}\text { Model 1 } & 0.86 & 0.18 & 4.05 & .85 \\ \text { Model 2 } & 0.83 & 0.18 & 3.92 & .81 \\ \text { Model 3 } & 0.86 & 0.18 & 4.05 & .84\end{array}$

Severe Hearing Loss

$\begin{array}{lllll}\text { Model 1 } & 2.65 & 0.29 & 24.33 & .39 \\ \text { Model 2 } & 2.45 & 0.27 & 22.62 & .43 \\ \text { Model 3 } & 2.27 & 0.24 & 21.85 & .48\end{array}$

\section{Depression symptoms}

Mild Hearing Loss

$\begin{array}{lcccc}\text { Model 1 } & 1.43 & 1.20 & 1.70 & <.001 \\ \text { Model 2 } & 1.38 & 1.16 & 1.64 & <.001 \\ \text { Model 3 } & 1.36 & 1.15 & 1.61 & <.001\end{array}$

Severe Hearing Loss

$\begin{array}{lllll}\text { Model 1 } & 1.90 & 1.39 & 2.60 & <.001 \\ \text { Model 2 } & 1.75 & 1.29 & 2.38 & <.001 \\ \text { Model 3 } & 1.69 & 1.15 & 2.30 & <.001\end{array}$

Model 1: adjusted for sex, age, centre

Model 2: adjusted for sex, age, centre, education, income, marital status, psychotropic medication use Model 3: adjusted for sex, age, centre, education, income, marital status, psychotropic medication use, MMSE, functional ability, falls, BMI, hypertension, diabetes, smoking, alcohol consumption, and history of stroke and myocardial infarction MDD analyses: Model $1 \mathrm{n}=8003$; Model $2 \mathrm{n}=7984$; Model $3 \mathrm{n}=7927$

Depression analyses: Model $1 n=6665$; Model $2 n=6657$; Model $3 n=6614$ 


\section{Figure Legend:}

Figure 1: Flow chart of participants 


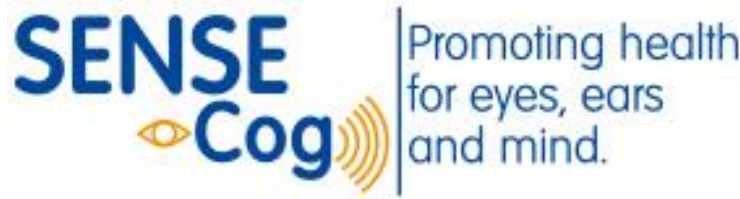

\section{*Authorlist for Sense-Cog WP1 consortium}

Geir Bertelsen ${ }^{1,2}$, Suzanne Cosh $^{3}$, Audrey Cougnard-Grégoire ${ }^{3}$, Piers Dawes ${ }^{4}$, Cécile Delcourt ${ }^{3}$, Fofi Constantinidou $^{5}$, Catherine Helmer ${ }^{3}$, M. Arfan Ikram ${ }^{6,7}$, Caroline CW Klaver ${ }^{6,8}$, Iracema Leroi ${ }^{9}$, Asri Maharani ${ }^{9,10}$, Magda Meester-Smor ${ }^{6,8}$, Unal Mutlu ${ }^{6,8}$, Virginie Nael ${ }^{3,11,12}$, Neil Pendleton ${ }^{9,10}$, Henrik Schirmer ${ }^{13}$, Gindo Tampubolon ${ }^{14}$, Henning Tiemeier ${ }^{6,15}$, Therese von Hanno ${ }^{16,17}$.

1: UiT The Arctic University of Norway, Department of Community Medicine, Faculty of Health Sciences, N-9037 Tromsø, Norway

2: University Hospital of North Norway, Department of ophthalmology, N-9038 Tromsø, Norway

3: Univ. Bordeaux, Inserm, Bordeaux Population Health Research Center, team LEHA, UMR 1219, F33000 Bordeaux, France

4: University of Manchester, Manchester Centre for Audiology and Deafness, School of Health Sciences, Manchester, UK

5: University of Cyprus, Department of Psychology \& Center for Applied Neuroscience, Nicosia, Cyprus

6: Erasmus Medical Centre, Department of Epidemiology, Rotterdam, The Netherlands

7: Erasmus Medical Centre, Departments of Neurology and Radiology, Rotterdam, The Netherlands

8: Erasmus Medical Centre, Department of Ophthalmology, Rotterdam, The Netherlands

9: University of Manchester, Division of Neuroscience and Experimental Psychology, School of

Biological Sciences, Manchester, UK

10: University of Manchester, Academic Health Science Centre, Manchester, UK

11: Sorbonne University, UMPC University of Paris 06, INSERM, CNRS, Vision Institute, F-75012

Paris, France

12: R\&D Life and Vision Science, Essilor International, F-75012 Paris, France

13: UiT-The Arctic University of Norway, Department of Clinical Medicine, Cardiovascular research Group-UNN, N-9037 Tromsø, Norway

14: University of Manchester, Global Development Institute, Manchester, UK

15: Erasmus Medical Centre, Department of Psychiatry, Rotterdam, The Netherlands

16: UiT-The Arctic University of Norway, Department of Clinical Medicine, Faculty of Health Sciences, N-9037 Tromsø, Norway

17: Nordland Hospital, Department of Ophthalmology, N-8092 Bodø, Norway 